\title{
A physical activity barriers questionnaire for youth with visual impairments
}

\author{
Ellen Armstrong ${ }^{1}$, Lauren Lieberman ${ }^{2}$, Eva Prokešová ${ }^{3, *}$, Jeffrey Martin $^{4}$
}

1 Griffith University, Brisbane, Australia

2 The College at Brockport, State University of New York, USA

3 Faculty of Physical Education and Sport, Charles University, Prague, Czech Republic

${ }^{4}$ Wayne State University, Detroit, Michigan, USA

* Corresponding author: eprokesova@ftvs.cuni.cz

\begin{abstract}
Background. In the current paper we examined the psychometric properties of the Physical Activity Barriers Questionnaire for children with Visual Impairments (PABQ-VI). We examined evidence for the ability of the PABQ-VI to produce scores considered to be valid and exhibit internal reliability.

Methods. Forty one children living in the USA who were attending a residential sports camp participated in our research. Psychometric properties of the PABQ-VI were investigated using Pearson product-moment coefficients, Cronbach's alpha and split-half reliability tests. Convergent validity was established by exploring correlations between the PABQ-VI, physical activity (PA) levels and participant's self-efficacy for overcoming barriers.

Results. Participants demonstrated low PA levels. Both PA participation and barrier PA self-efficacy scores were correlated with the PABQ-VI. The most physically active participants perceived fewer barriers and had stronger efficacy compared to participants who were less physically active.

Conclusions. Overall, the PABQ-VI demonstrated preliminary evidence of convergent validity. Future researchers may consider reducing participant burden by reducing the scale length through eliminating the most poorly performing items and examining the three-factor structure using factor analysis.
\end{abstract}

\section{KEYWORDS}

exercise; disability; adapted sport; blind

DOI

10.14712/23366052.2018.4

(c) 2018 The Authors. This is an open-access article distributed under the terms of the Creative Commons Attribution License (http://creativecommons.org/licenses/by/4.0), which permits unrestricted use, distribution, and reproduction in any medium, provided the original author and source are credited. 


\section{INTRODUCTION}

Children and adolescents with visual impairments (VI) tend to be sedentary and engage in low levels of physical activity (PA) in absolute levels and relatively when compared to comparably aged peers (Augestad \& Jiang, 2015; Greguol, Gobbi, \& Carraro, 2014; Haegele \& Porretta, 2015; Lieberman, Byrne, Mattern, Watt, \& Fernandez-Vivo, 2010). The reasons for low PA range from limited opportunities to be active, especially when young (Greguol, Gobbi, \& Carraro, 2014; Perkins, Columna, Lieberman, \& Bailey, 2013), which can promote developmental delays in motor skill acquisition. Additionally a lack of fitness, poor and inefficient gait patterns, and psychosocial variables (e.g., lack of interest, few friends) contribute to limited PA (Lieberman, Byrne, Mattern, Watt, \& Fernandez-Vivo, 2010; Wagner, Haibach, \& Lieberman, 2013).

However, researchers have indicated that youth with VI can achieve healthy levels of fitness and adequate motor skills when they engage in PA (Perkins, Columna, Lieberman, \& Bailey, 2013). In order for educators and parents to provide quality PA opportunities it is helpful to understand the most common PA barriers that limit youth with VI from participating in PA. Identifying these barriers early in life is critical because childhood PA experiences influence later life PA participation (Telama, Yang, Leskinen, Kankaanpää, Hirvensalo, Tammelin, Viikari, \& Raitakari, 2014).

In a recent literature review on PA and school-aged children with VI, Haegele and Porretta (2015) urged researchers to conduct theory-driven PA interventions that address barriers over multiple domains. However, research that can guide PA interventions is constrained by a lack of scales that can be used to identify PA barriers among youth with VI. Current measures such as the Exercise Benefits and Barriers Scale (Sechrist, Walker, \& Pender, 1987) and the Perceived Barriers to Exercise Scale (Salmon, Owen, Crawford, Bauman, \& Sallis, 2003) do not address barriers unique to people with VI. For example, barriers relating to policy, accessibility, a lack of sight, and fear of stigmatization are missing from the above noted scales (Kissow, 2015; Shields, Synnot, \& Barr, 2012). Although two PA barrier scales have recently been developed for people with VI both scales were developed specifically for adults and fail to address barriers specific to children and adolescents (Jaarsma, Dekker, Koopmans, Dijkstra, \& Geertzen, 2014; Lee, Zhu, Ackley-Holbrook, Brower, \& McMurray, 2014).

Children spend a large proportion of time at school or with peers, and therefore perceive barriers that adults with VI do not encounter. Similarly, we know that parental support heavily influences the PA levels of children with VI (Greguol, Gobbi, \& Carraro, 2014; Perkins, Columna, Lieberman, \& Bailey, 2013; Stuart, Lieberman, \& Hand, 2006). Hence, parent-linked barriers such as over-protection and beliefs that children can't participate in PA contribute to the barriers experienced by youth with VI. For these reasons, questionnaires developed for adults are not ideal for research involving youth with VI.

To facilitate future research on PA barriers of youth with VI, the Physical Activity Barriers Questionnaire for Children with Visual Impairments (PABQ-VI) was developed (Armstrong, Lieberman, Guerrero, \& Martin, in review). While the PABQ-VI demonstrated initial adequate validity and reliability, a small sample size was a weakness and additional research examining validity and reliability is needed. The PABQVI is based in social cognitive theory (SCT) and initial research (Armstrong, Lieberman, Guerrero, \& Martin, in review) indicates it can produce scores that provide 
evidence of validity and reliability. In the current study we extended prior work on the PABQ-VI (Armstrong, Lieberman, Guerrero, \& Martin, in review) and provided additional evidence of its ability to produced scores deemed valid and reliable.

The PABQ-VI is based on Bandura's SCT which asserts that a person's behavior, their environment and personal factors all exert reciprocal influences on each other (Bandura, 2004; Ramirez, Kulinna, \& Cothran, 2012). SCT recognizes that health behaviors are influenced by an individual's outcome expectations, goals and perceived barriers, in addition to their self-efficacy (SE; Bandura, 2004). Researchers have found that SE directly predicts PA and related SCT constructs such as perceived barriers (Ayotte, Margrett, \& Hicks-Patrick, 2010). In other words, if a person has low SE, they are likely to perceive many barriers to PA, exhibit low outcome expectations, have difficulty establishing PA related goals and ultimately avoid PA participation (Allison \& Keller, 2004; Ayotte, Margrett, \& Hicks-Patrick, 2010).

In the current study we continue to examine validity (i.e., convergent) by examining if the PABQ-VI is positively linked to PA and self-efficacy. We also employed a larger sample to achieve these purposes relative to the initial validation sample (Armstrong, Lieberman, Guerrero, \& Martin, in review).

\section{METHODS}

\section{Participants}

Participants were a convenience sample of 41 youth with VI (18 F, $23 \mathrm{M})$, aged from 8 to 18 years $(\mathrm{M}=12.98)$, who attended a sports camp in America in 2015 (see Table 1). The B1-B4 classification system (United States Association of Blind Athletes, 2016) was used to classify level of vision, because this was the system used to enroll children in the American camp. B1 classification refers to no functional vision and B4 refers to visual acuity from $20 / 200$ up to $20 / 70$ in the better eye with correction, or a visual field of greater than 20 degrees. Gender breakdown via classification was as follows: B1 (6 F, $3 \mathrm{M}), \mathrm{B} 2(5 \mathrm{~F}, 5 \mathrm{M}), \mathrm{B} 3(5 \mathrm{~F}, 11 \mathrm{M}), \mathrm{B} 4$ (2 F, $4 \mathrm{M})$.

\section{Instrumentation}

Physical Activity. The Physical Activity Questionnaire for Children and Adolescents (PAQ-C/-A) (Kowalski, Crocker, \& Donen, 2004) was used to assess participant's PA levels. This questionnaire has been used previously among youth with VI and shown evidence it can produce scores considered valid and reliable (Greguol, Gobbi, \& Carraro, 2014).

$P A B Q-V I$. The Physical Activity Barrier Questionnaire-Visually Impaired (Armstrong, Lieberman, Guerrero, \& Martin, in review) was used with minor changes made to the wording of four items (items 4, 23, 32, 34) to better suit an American audience. For example, the term play-time was replaced with recess in item 23 . An open-ended question was included at the end of the PABQ-VI, allowing children to report additional barriers to PA. The anchors for the 5-point likert scale used in this study were as follows, $1=$ strongly disagree and $5=$ strongly agree.

PASES. The Physical Activity Self-Efficacy Scale contains eight items and participants responded by circling 'yes' 'unsure' or 'no'. For example, item 1 from the PASES was "I can be physically active most days after school". 


\section{Test administration and data analysis}

Upon receiving ethical approval, trained camp counselors, who were paired one-onone with campers throughout the week, dictated the PABQ-VI to their campers using identical scripts. Large print copies were provided to participants who wished to read along and braille versions were also available. Data analysis was completed using IBM SPSS version 21 . No estimation or adjustments were required for missing items.

\section{RESULTS}

Descriptive statistics can be found in Table 1a and Table $1 \mathrm{~b}$. An independent-samples t-test was run to see if there were any differences in PABQ-VI, PAQ or PASES scores for level of vision, gender or age. Homogeneity of variances was confirmed for all comparisons based on Levene's Test for Equality of Variance ( $p>0.05$ ), except for the comparison of male vs female PASES scores. Effect-sizes (r) were also calculated.

Table 1a Participant Demographics and Measurement Scores

\begin{tabular}{l|c|c|c}
\hline Characteristic & $\boldsymbol{n}(\mathbf{M} \pm \mathbf{S D})^{\mathbf{a}}$ & Range & VAR $^{\mathbf{b}}$ \\
\hline Gender & & & \\
\hline Male & 23 & & \\
\hline Female & 18 & & \\
\hline Level of vision & 9 & & \\
\hline B1 & 10 & & \\
\hline B2 & 16 & & \\
\hline B3 & 6 & & \\
\hline B4 & $12.98 \pm 2.286$ & 10.00 & \\
\hline Age & $2.26 \pm 0.583$ & 2.34 & 0.34 \\
\hline PAQ Score & $154.15 \pm 25.67$ & 103.00 & 659.18 \\
\hline PABQ-VIScore & $1.50 \pm 0.435$ & 1.50 & 0.19 \\
\hline PASES Score & & & \\
\hline
\end{tabular}

${ }^{\mathrm{a}}$ Mean \pm Standard Deviation

${ }^{\mathrm{b}}$ Variance

Table 1b Ms, SDs for all variables

\begin{tabular}{c|c|c|c}
\hline Vision Level & PABQ-VI & PASES & PAQ \\
\hline B1 & $167.8(19.1)$ & $1.75(0.25)$ & $2.42(0.48)$ \\
\hline B2 & $150.2(28.1)$ & $1.46(0.35)$ & $1.83(0.58)$ \\
\hline B3 & $156.9(24.6)$ & $1.43(0.50)$ & $2.53(0.43)$ \\
\hline B4 & $132.8(22.6)$ & $1.17(0.46)$ & $2.04(0.71)$ \\
\hline
\end{tabular}


For the PAQ assessing PA levels, significant differences existed between groups $\mathrm{B} 1$ and $\mathrm{B} 2$ as well as $\mathrm{B} 2$ and $\mathrm{B} 3$. Children with $\mathrm{B} 1$ vision were more active $(M=2.42$, $S D=0.477)$ than children with B2 vision $(M=1.83, S D=0.58) ; t(17)=2.40, p=0.028$; effect-size $\mathrm{r}=0.5$, and children with B3 vision were also more active $(M=2.53$, $S D=0.425)$ than those with B2 vision $(M=1.83, S D=0.58) ; t(24)=-3.56, p=0.002$; effect-size $r=0.57$.

For PABQ-VI scores, significant differences were identified for level of vision, between groups B1 and B4, and groups B3 and B4 only. Children in the B1 group ( $M=167.78, S D=19.13$ ) had significantly higher PABQ-VI scores (fewer barriers) compared to those with B4 vision $(M=132.83, S D=22.59) ; t(13)=-3.230, p=0.007$; effect-size $r=0.64$. Similarly, children with B3 vision scored higher on the PABQVI $(M=156.94, S D=24.61)$ than those with B4 vision $(M=132.83, S D=22.59)$; $t(20)=2.09, p=0.05$; effect-size $\mathrm{r}=0.45$. Between-group differences were also found for gender, with males reporting significantly fewer barriers (higher PABQ-VI scores $)(M=163.70, S D=22.46)$ than females $(M=141.90, S D=24.84) ; t(39)=2.94$, $p=0.006$; effect-size $\mathrm{r}=0.42$.

For PASES, significant differences were found for level of vision, between groups $\mathrm{B} 1$ and B4 only. Children in the B1 group scored higher on the PASES $(M=1.75$, $S D=0.251)$ compared to children in the B4 group $(M=1.17, S D=0.460) ; t(13)=3.20$, $p=0.007$; effect-size $\mathrm{r}=0.62$. Boys also scored significantly higher on the PASES $(M=1.65, S D=0.344)$ compared to girls $(M=1.31, S D=0.47) ; t(30)=2.56, p=0.016$; effect-size $r=0.38$. Homogeneity of variance could not be assumed for this gender comparison, according to Levene's Test for Equality of Variances $(p=0.037)$, so separate variances were used.

Similar to the initial PABQ-VI validation study, the frequency distribution of likert-scale responses from the PABQ-VI was skewed in the positive direction and the median response across all items was 4, corresponding to the label 'I agree'.

\section{Convergent validity}

PABQ-VI scores were correlated with PA levels $\left(r=0.44, \mathrm{p}<0.01\right.$, effect-size $\left.\mathrm{r}^{2}=0.2\right)$ and the PASES $\left(r=0.66, \mathrm{p}<0.01\right.$; effect-size $\left.\mathrm{r}^{2}=0.44\right)$, meaning that participants who were active and had high levels of PA self-efficacy perceived fewer PA barriers. Active participants also demonstrated higher PA self-efficacy $(r=0.32, \mathrm{p}<0.05$; effect-size $\left.\mathrm{r}^{2}=0.1\right)$. These correlations provide some evidence of convergent validity.

\section{Item-total correlations for the $\mathrm{PABQ}-\mathrm{VI}$ subscales}

Item-scale correlations for the PABQ-VI sub-scales are provided in Table 2. Personal scale items correlated most strongly with their intended subscale with a few cross-loadings. Similarly, all environmental barrier items correlated most strongly with the environmental subscale, with the exception of item 31 . Ten social barrier items correlated most strongly with the social subscale as expected, although the eight remaining social items correlated more strongly the remaining subscales or no subscale at all. In total, eight items (items $3,11,12,14,19,25,28,31$ ) did not correlate significantly with the PABQ-VI as a whole and five of these were reverse-scored items. 
Table 2 Item-total correlations for PABQ-VI subscales

\begin{tabular}{|c|c|c|c|c|c|}
\hline \multicolumn{2}{|c|}{ Item } & PER* & SOC* & ENV* & Total* \\
\hline \multicolumn{6}{|c|}{ Personal Barriers } \\
\hline 1 & I believe physical activity is important. & $0.660^{* *}$ & $0.364^{*}$ & $0.372^{*}$ & $0.503^{* *}$ \\
\hline 2 & I feel motivated to do physical activity. & $0.618^{* *}$ & $0.364^{*}$ & $0.400^{* *}$ & $0.502^{* *}$ \\
\hline 3 & $\begin{array}{l}\text { I think I have enough time after homework and chores to } \\
\text { do physical activity. }\end{array}$ & $0.471^{* *}$ & 0.110 & 0.122 & 0.234 \\
\hline 4 & I know how to do physical activity if I want to. & $0.459 * *$ & 0.278 & $0.401^{* *}$ & $0.419^{* *}$ \\
\hline 5 & $\begin{array}{l}\text { I believe I can do physical activity even though I have } \\
\text { a visual impairment. }\end{array}$ & $0.535^{* *}$ & $0.352^{*}$ & $0.337^{*}$ & $0.447^{* *}$ \\
\hline 6 & $\begin{array}{l}\text { Sport and physical activities are fun because l'm good at } \\
\text { them. }\end{array}$ & $0.475^{* *}$ & $0.350^{*}$ & $0.316^{*}$ & $0.421^{* *}$ \\
\hline 7 & I feel confident to try new sports and physical activities. & $0.549 * *$ & $0.501^{* *}$ & $0.534^{* *}$ & $0.598^{* *}$ \\
\hline 8 & $\begin{array}{l}\text { I like how my body looks and feels when I do physical } \\
\text { activity. }\end{array}$ & $0.675^{* *}$ & $0.328^{*}$ & $0.418^{* *}$ & $0.510^{* *}$ \\
\hline 9 & I'm scared to get hurt when I do physical activity. & $0.512^{* *}$ & $0.505^{* *}$ & $0.346^{*}$ & $0.512^{* *}$ \\
\hline 10 & Physical activity and sports are fun. & $0.627^{* *}$ & $0.314^{*}$ & $0.405^{* *}$ & $0.485^{* *}$ \\
\hline 11 & $\begin{array}{l}\text { Physical activity makes me very tired because I have } \\
\text { a visual impairment. }\end{array}$ & $0.417^{* *}$ & 0.121 & 0.254 & 0.277 \\
\hline 12 & $\begin{array}{l}\text { My vision impairment does not keep me from doing } \\
\text { physical activity. }\end{array}$ & $0.537^{* *}$ & 0.111 & 0.243 & 0.302 \\
\hline
\end{tabular}

Social Barriers

\begin{tabular}{|c|c|c|c|c|c|}
\hline 13 & My parents have time to do physical activity with me. & 0.301 & $0.659 * *$ & 0.306 & $0.504^{* *}$ \\
\hline 14 & My parents show me how to do physical activity. & 0.091 & $0.502^{* *}$ & 0.097 & 0.289 \\
\hline 15 & My parents encourage me to do physical activity. & $0.343^{*}$ & $0.532^{* *}$ & 0.248 & $0.436^{* *}$ \\
\hline 16 & $\begin{array}{l}\text { My parents can afford for me to do sport and physical } \\
\text { activity. }\end{array}$ & 0.249 & $0.429 * *$ & $0.499 * *$ & $0.465^{* *}$ \\
\hline 17 & My parents expect me to do physical activity. & $0.568^{* *}$ & $0.710^{* *}$ & $0.626^{* *}$ & $0.734^{* *}$ \\
\hline 18 & $\begin{array}{l}\text { My parents believe that physical activity is just as } \\
\text { important as school. }\end{array}$ & 0.259 & $0.463^{* *}$ & 0.297 & $0.401^{* *}$ \\
\hline 19 & $\begin{array}{l}\text { My parents worry about my safety when I do physical } \\
\text { activity. }\end{array}$ & 0.073 & 0.155 & -0.080 & 0.057 \\
\hline 20 & Physical activity is important to my parents. & $0.358^{*}$ & $0.648^{* *}$ & $0.427^{* *}$ & $0.565^{* *}$ \\
\hline 21 & $\begin{array}{l}\text { My parents have time to take me to sport even if my } \\
\text { brothers or sisters also play sport. }\end{array}$ & 0.234 & $0.391 *$ & $0.392 *$ & $0.401 * *$ \\
\hline 22 & $\begin{array}{l}\text { My parents have a way to get me to places to do sport or } \\
\text { physical activity. }\end{array}$ & $0.452^{* *}$ & $0.334^{*}$ & $0.409 * *$ & $0.445^{* *}$ \\
\hline 23 & $\begin{array}{l}\text { My classmates include me in games and physical activi- } \\
\text { ties during play time. }\end{array}$ & $0.379^{*}$ & $0.690^{* *}$ & $0.551^{* *}$ & $0.640^{* *}$ \\
\hline
\end{tabular}




\begin{tabular}{|c|c|c|c|c|c|}
\hline 24 & $\begin{array}{l}\text { I know other children who will do physical activity with } \\
\text { me. }\end{array}$ & 0.145 & $0.513^{* *}$ & $0.346^{*}$ & $0.410^{* *}$ \\
\hline 25 & $\begin{array}{l}\text { Other kids have made fun of me during sports or physical } \\
\text { activity. }\end{array}$ & $0.351^{*}$ & 0.291 & 0.141 & 0.288 \\
\hline 26 & $\begin{array}{l}\text { My teachers expect me to do physical activity just like } \\
\text { everyone else. }\end{array}$ & 0.273 & $0.566^{* *}$ & $0.574^{* *}$ & $0.564^{* *}$ \\
\hline 27 & My PE teacher encourages me to do physical activity. & $0.348^{*}$ & $0.623 *$ & $0.665^{* *}$ & $0.648^{* *}$ \\
\hline 28 & $\begin{array}{l}\text { My teacher worries about my safety when I do physical } \\
\text { activity. }\end{array}$ & 0.154 & $0.381 *$ & 0.061 & 0.239 \\
\hline 29 & $\begin{array}{l}\text { My PE teacher makes changes to games and activities so } \\
\text { I can participate. }\end{array}$ & 0.273 & $0.453^{* *}$ & $0.423^{* *}$ & $0.452^{* *}$ \\
\hline 30 & $\begin{array}{l}\text { My PE teacher includes me in games and physical } \\
\text { activities. }\end{array}$ & 0.304 & $0.534^{* *}$ & $0.579 * *$ & $0.560^{* *}$ \\
\hline
\end{tabular}

Environmental Barriers

\begin{tabular}{|c|c|c|c|c|c|}
\hline 31 & $\begin{array}{l}\text { People in my community don't expect that I can do } \\
\text { physical activity. }\end{array}$ & 0.069 & 0.183 & 0.165 & 0.169 \\
\hline 32 & $\begin{array}{l}\text { I know about opportunities to do physical activity outside } \\
\text { of school. }\end{array}$ & $0.698^{* *}$ & $0.536^{* *}$ & $0.746^{* *}$ & $0.742^{* *}$ \\
\hline 33 & $\begin{array}{l}\text { There are sport programs or physical activities available in } \\
\text { my community. }\end{array}$ & $0.541^{* *}$ & $0.376^{*}$ & $0.696^{* *}$ & $0.606^{* *}$ \\
\hline 34 & $\begin{array}{l}\text { There are sighted guides who can help me do physical } \\
\text { activity in my community. }\end{array}$ & 0.237 & $0.390^{*}$ & $0.509 * *$ & $0.449^{* *}$ \\
\hline 35 & $\begin{array}{l}\text { There are sports or activities that I can join which are } \\
\text { close to home. }\end{array}$ & $0.527^{* *}$ & $0.490^{* *}$ & $0.792^{* *}$ & $0.692^{* *}$ \\
\hline 36 & $\begin{array}{l}\text { There are places in my community that are safe for me to } \\
\text { do physical activity. }\end{array}$ & $0.526^{* *}$ & $0.718^{* *}$ & $0.790^{* *}$ & $0.792^{* *}$ \\
\hline 37 & $\begin{array}{l}\text { Sports clubs in my community allow me to join even } \\
\text { though I have a visual impairment. }\end{array}$ & $0.522^{* *}$ & $0.567^{* *}$ & $0.828^{* *}$ & $0.739 * *$ \\
\hline 38 & $\begin{array}{l}\text { I have sports equipment at home that I can use to be } \\
\text { physically active. }\end{array}$ & $0.405^{* *}$ & $0.546^{* *}$ & $0.789 * *$ & $0.680^{* *}$ \\
\hline 39 & $\begin{array}{l}\text { There are spaces at home that are safe for me to do } \\
\text { physical activity. }\end{array}$ & $0.411^{* *}$ & $0.663^{* *}$ & $0.753^{* *}$ & $0.719 * *$ \\
\hline 40 & I have to participate in PE class because it is a school rule. & 0.214 & $0.368^{*}$ & $0.432^{* *}$ & $0.401^{* *}$ \\
\hline 41 & $\begin{array}{l}\text { My school have physical activity equipment for people } \\
\text { with visual impairment. }\end{array}$ & 0.276 & 0.203 & $0.511^{* *}$ & $0.377^{*}$ \\
\hline 42 & $\begin{array}{l}\text { My school has sport teams and physical activity clubs that } \\
\text { I can join if I want to. }\end{array}$ & $0.448^{* *}$ & $0.544^{* *}$ & $0.667^{* *}$ & $0.642^{* *}$ \\
\hline
\end{tabular}

Note: Items that did not correlate significantly with any subscale are highlighted in grey; Significant correlations are in boldface, except in cases where cross-loading has occurred and the difference between correlations is greater than 0.20 ; ** Correlation is significant at the 0.01 level (2-Tailed); ${ }^{*}$ Correlation is significant at the 0.05 level (2-Tailed). PER $=$ Personal barriers, $\mathrm{SOC}=$ Social barriers, ENV $=$ Environmental barriers, Total $=$ Total PABQ-VI score. 


\section{Internal consistency reliability}

The PABQ-VI demonstrated good internal consistency with a Cronbach's alpha coefficient of 0.92 and split half reliability of 0.87 . When analyzed as separate scales, the environmental subscale was most internally consistent $(\alpha=0.86$, split-half reliability $=0.83)$, followed by the social $(\alpha=0.81$, split-half reliability $=0.67)$ and personal subscales $(\alpha=0.77$, split-half reliability $=0.78)$. Mean inter-item correlations were reasonable $(0.54,0.50$ and 0.63$)$ for the personal, social and environmental subscales, respectively.

\section{DISCUSSION}

As noted by Hubley and Zumbo (2011) validation is a continuous process that involves lots of different types of evidence to illustrate if scores produced within a given context by a particular sample are supportive of validity and reliability. Further, they emphasize that validity concerns the interpretation and consequences of the test scores and is not a fixed or static property of the measure itself (Hubley \& Zumbo, 2011). Hence the current sample and context in which the present findings are based is important for the reader to bear in mind. Future researchers using the PABQ-VI should always remember that the current scale assesses a theoretical construct (PA barriers) and is designed to produces scores relevant to children with VI.

Findings from the current study mostly align with the findings from the initial research study (Armstrong, Lieberman, Guerrero, \& Martin, in review) as PABQ-VI responses were positively skewed in the current study, increasing from 'strongly disagree' to 'strongly agree', with the median response being 'I agree'. The tendency for participants in both studies to respond agreeably with PABQ-VI items might reflect that in both studies participants were enrolled in VI-specific sports camps whose goal it was to engage camp participants in PA. Nonetheless, the PABQ-VI was able to yield a consistent distribution of responses across both samples.

In the current study the highest ranked questions were items 1, 4 and 5 (all personal barriers). This finding mirrored the same finding from the initial validation study (Armstrong, Lieberman, Guerrero, \& Martin, in review). The finding suggests that both Irish and American children recognize PA as important (item 1); believe they can be active regardless of their VI (item 5) and are aware of ways to do PA (item 4). Item 5 (I believe I can do PA even though I have a VI) was the absolute highest scoring item, with $71.4 \%$ of participants in Study 1 and $82.9 \%$ of participants in Study 2 responding with 'strongly agree'. This consensus across both studies may reflect that children with VI do not consider their VI as a major barrier to PA, but perceive other factors as most limiting (Greguol, Gobbi, \& Carraro, 2014; Perkins, Columna, Lieberman, \& Bailey, 2013).

In support of the latter idea, findings from the current study and initial validation study indicate that both social and environmental factors such as a lack of sighted guides (item 34), parents' concerns for safety (item 19), PE teachers' ability/willingness to adapt activities (item 29) and a lack of specialized PA equipment at school (item 41) are important. These findings are supported by current barrier research that has identified parent, peer and teacher-related barriers as well as policy and environmental barriers as pertinent to children with VI (Greguol, Gobbi, \& Carraro, 2014; Stuart, Lieberman, \& Hand, 2006). Collectively, ourfindings provide preliminary evidence of validity in support of the PABQ-VI. 


\section{Convergent validity}

Our sample demonstrated low levels of PA. Participants in the current study fell below age and gender norms for the PAQ-C/-A (Voss, Ogunleye, \& Sandercock, 2013). Despite a tendency toward physical inactivity, children who engaged in more PA perceived fewer PA barriers, which emulates findings from research on people with disabilities including VI (Jaarsma, Dekker, Koopmans, Dijkstra, \& Geertzen, 2014) and provides validity evidence.

The PASES was correlated significantly with PABQ-VI scores with a small to moderate effect-size of $=0.44$, providing evidence of convergent validity.

\section{Differences for gender and level of vision}

The PABQ-VI was also able to discriminate between participants based on level of vision and gender. In the initial validation study, participants with low vision were more active and reported fewer PA barriers than those who were blind and that finding was consistent with work by Stuart and colleagues (Stuart, Lieberman, \& Hand, 2006) who found that PA barriers differed according to level of vision and, Holbrook et al. who observed that blind participants were less active than those with low vision (Holbrook, Caputo, Perry, Fuller, \& Morgan, 2009).

A similar relationship between level of vision and PA was found in the current study with the exception of B1 and B2 classifications. A possible explanation for this might be that the difference in level of vision between B1 and B2 classifications might be insufficient to cause the group with lower vision to be any more limited than those with some vision.

We also found differences in PASES scores for level of vision and gender. The finding that B1 participants had higher PASES and fewer PA barriers than B4 participants was unexpected, but serves as a reminder that a person's perception of barriers and SE for overcoming barriers may be influenced by more than just the severity of VI. In fact, children who are blind have been known to achieve healthy levels of PA when provided with the opportunities to do so (Blessing, McCrimmon, Stovall, \& Williford, 1993).

In terms of gender, boys had higher SE and fewer PA barriers compared to girls, but no differences were found for PA level. Aslan, Calik and Kitis (2012) found that boys with low vision were significantly more active than girls with low vision, but this was not true for participants who were blind. Most authors have not identified a gender bias for PA engagement among children with VI, which is a phenomenon that exists among sighted peers (Greguol, Gobbi, \& Carraro, 2014). It is possible that the absence of a gender bias reflects the global lack of opportunities for children with VI to participate in PA, regardless of gender (Shapiro, Moffett, Lieberman, \& Dummer, 2005). The significantly higher SE and fewer barriers reported by boys is consistent with findings by Shapiro and colleagues (2005) who found boys to have higher percieved competence for PA compared to girls.

\section{Item scale correlations and the proposed three-factor structure}

In terms of item-scale correlations, the PABQ-VI had 10 items that failed to correlate with their intended subscale in the initial validation study. In the current study only 2 items failed to correlate with any of the subscales, including the overall PABQ-VI. These were item 19, "My parents worry about my safety when I do PA", and item 31, 
"People in my community don't expect that I can do PA". Interestingly, both of these reverse-scored items (19 and 31) did not correlate significantly in the initial developmental study (Armstrong, Lieberman, Guerrero, \& Martin, in review) either.

Overall, the majority of items throughout the PABQ-VI correlated with their intended subscale, however a few items cross-loaded (Table 2). Cross-loading is not ideal because it shows that these items are unable to discriminate as intended. However, viewed with a social-cognitive lens, PA barriers that are considered personal and environmental should be expected to interact to influence PA behavior, rather than operating exclusively (Ramirez, Kulinna, \& Cothran, 2012).

For example, the item "Physical activity and sports are fun" (item 10), was developed to address the barrier 'lack of enjoyment of PA'. Although 'enjoyment' is a feeling generated from within a person, enjoyment can certainly be contingent on social (e.g., friends) or environmental (a nice well-kept soccer pitch) factors.

In order to demonstrate relevance and utility of the PABQ-VI for children with VI, it is essential to include items across multiple domains to reflect the variety of barriers experienced by this population. However, the decision to interpret PABQ-VI results as a single scale or as three subscales depends on the user's goals and the context. For example, analyzing data as three separate subscales might be useful when comparing findings across different groups. In contrast, a single barrier score might be appropriate to track general changes in perceived barriers before and after an intervention. The inclusion of an open question at the end of the PABQ-VI allows researchers to identify additional barriers that could be useful to inform PA program development.

The small sample size prevented a factor analysis to examine the proposed three-factor structure of the PABQ-VI. However, given the adequate internal consistency evidence for the three subscales in the current and initial study it is not recommended that any items are deleted from the PABQ-VI at this time.

\section{Limitations}

The most obvious limitation to our study was the low sample size. Future researchers should aim for larger samples that allow for more sophisticated analyses and to reliably reduce scale length by losing the most poorly performing items. A greater diversity of participants would be beneficial in the future to test the generalizability of results. The PAQ-C/PAQ-A is a subjective self-report scale so objective measures of PA (e.g., pedometers) are needed to more fully investigate the relationship between PA participation and barriers. Finally, test-retest reliability was not investigated in the current study and data on test-retest would be helpful. Researchers who wish to apply the questionnaire in its preliminary form should be aware of these limitations, interpret results with caution and seek to address these concerns in future studies.

\section{Conclusions and future directions}

Despite the aforementioned weaknesses, we showed that the 42-item PABQ-VI has strong potential to identify PA barriers among children with VI across multiple domains. We conclude that the PABQ-VI demonstrates initial evidence of internal consistency and validity when correlated with PA and SE. Furthermore, the frequency distribution of PABQ-VI responses and the ability of the PABQ-VI to discriminate between population sub-groups support the evidence of validity. 
In support of a unified validity theory, Hubley and Zumbo (2011, p. 220) argue that validity is "the degree to which all of the accumulated evidence supports the intended interpretation of test scores for the proposed purpose". Future efforts to validate the PABQ-VI for this purpose will focus on recruiting sufficient participant numbers to investigate the three-factor structure as well as performing item by item analyses and test re-test reliability.

\section{REFERENCES}

Allison, M. J., \& Keller, C. (2004). Self-efficacy intervention effect on physical activity in older adults. Western Journal of Nursing Research, 26(1), 31-46.

Armstrong, Lieberman, Guerrero, \& Martin, in review.

Aslan, U., Calik, B., \& Kitis, A. (2012). The effect of gender and level of vision on the physical activity level of children and adolescents with visual impairment. Research in Developmental Disabilities, 33(6), 1799-1804.

Augestad, L., \& Jiang, L. (2015). Physical activity, physical fitness, and body composition among children and young adults with visual impairments: A systematic review. Brittish Journal of Visual Impairment, 33(3), 167-182.

Ayotte, B. J., Margrett, J. A., \& Hicks-Patrick, J. (2010). Physical activity in middle-aged and young-old adults the roles of self-efficacy, barriers, outcome expectancies, self-regulatory behaviors and social support. Journal of Health Psychology, 15(2), 173-185.

Bandura, A. (2004). Health promotion by social cognitive means. Health Education o Behavior, 31(2), 143-164.

Blessing, D. L., McCrimmon, D., Stovall, J., \& Williford, H. N. (1993). The effects of regular exercise programs for visually impaired and sighted schoolchildren. Journal of Visual Impairment \& Blindness, 87(2), 50-52.

Greguol, M., Gobbi, E., \& Carraro, A. (2014). Physical Activity Practice Among Children and Adolescents with Visual Impairment - Influence of Parental Support and Percieved Barriers. Disability and Rehabilitation, 37(4), 327-330.

Haegele, J., \& Porretta, D. (2015). Physical activity and school-age individuals with visual impairments: a literature review. Adapted Physical Activity Quarterly, 32(1), 68-82.

Holbrook, E. A., Caputo, J. L., Perry, T. L., Fuller, D. K., \& Morgan, D. W. (2009). Physical activity, body composition, and perceived quality of life of adults with visual impairments. Journal of Visual Impairment \& Blindness, 103(1), 17-29.

Hubley, A. M., \& Zumbo, B. D. (2011). Validity and consequences of test interpretation and use. Social Indicators Research, 103(2), 219-230.

Jaarsma, E., Dekker, R., Koopmans, S., Dijkstra, P., \& Geertzen, J. (2014). Barriers to and Facilitators of Sports Participation in People With Visual Impairments. Adapted Physical Activity Quarterly, 31(3), 240-264.

Kissow, A. (2015). Participation in physical activity and the every day life of people with physical disabilities: a review of the literature. Scandinavian Journal of Disability Research, 17(2), 144-166.

Kowalski, K., Crocker, P., \& Donen, R. (2004, August). The Physical Activity Questionnaire for Older Children (PAQ-C) and Adolescents (PAQ-A) Manual. Retrieved from: http://www .dapatoolkit.mrc.ac.uk/documents/en/PAQ/PAQ manual.pdf.

Lee, M., Zhu, W., Ackley-Holbrook, E., Brower, D., \& McMurray, B. (2014). Calibration and validation of the Physical Activity Barrier Scale for persons who are blind or visually impaired. Disability and Health Journal, 7, 309-317.

Lieberman, L., Byrne, H., Mattern, C., Watt, C., \& Fernandez-Vivo, M. (2010). Health-related fitness of youths with visual impairments. Journal of Visual Impairment \& Blindness, 104(6), 349-359. 
Perkins, K., Columna, L., Lieberman, L., \& Bailey, J. (2013). Parents’ perceptions of physical activity for their children with visual impairments. Journal of Visual Impairment \& Blindness, 107(2), 131-142.

Ramirez, E., Kulinna, P., \& Cothran, D. (2012). Constructs of physical activity behaviour in children: the usefulness of social cognitive theory. Psychology of Sport and Exercise, 13(3), 303-310.

Salmon, J., Owen, N., Crawford, D., Bauman, A., \& Sallis, J. F. (2003). Physical activity and sedentary behavior: A population-based study of barriers, enjoyment, and preference. Health Psychology, 22(2), 178-188.

Sechrist, K., Walker, S., \& Pender, N. (1987). Development and psychometric evaluation of the exercise benefits/barriers scale. Research in Nursing and Health, 10(6), 357-365.

Shapiro, D., Moffett, A., Lieberman, L., \& Dummer, G. (2005). Perceived competence of children with visual impairments. Journal of Visual Impairment \& Blindness, 99(1), 15-25.

Shields, N., Synnot, A., \& Barr, M. (2012). Perceived barriers and facilitators to physical activity for children with disability: A systematic review. British Journal of Sports Medicine, 46(14), 989-997.

Stuart, M. E., Lieberman, L. J., \& Hand, K. E. (2006). Beliefs about physical activity among children who are visually impaired and their parents. Journal of Visual Impairment \& Blindness, 100(4), 223-234.

Telama, R., Yang, X., Leskinen, E., Kankaanpää, A., Hirvensalo, M., Tammelin, T., Viikari, J., \& Raitakari, O. (2014). Tracking of physical activity from early childhood through youth into adulthood. Medicine \& Science in Sports \& Exercise, 46(5), 955-962.

United States Association of Blind Athletes (2016, January 29). IBSA Visual Classifications. Retrieved from USABA: http://usaba.org/index.php/membership/visual-classifications /visual_classifications.

Voss, C., Ogunleye, A. A., \& Sandercock, G. R. (2013). Physical activity questionnaire for children and adolescents: English norms and cut - off points. Pediatrics International, 55(4), 498-507.

Wagner, M. O., Haibach, P. S., \& Lieberman, L. J. (2013). Gross motor skill performance in children with and without visual impairments - Research to practice. Research in Developmental Disabilities, 34(10), 3246-3252. 